\title{
ARTIGO
}

do https://doi.org/10.22481/rpe.v16i43.6993

\section{REMINISCÊNCIAS DE LICENCIANDOS EM CIÊNCIAS BIOLÓGICAS SOBRE O ENSINO DE CIÊNCIAS NA EDUCAÇÃO BÁSICA}

\author{
REMINISCENCES OF LICENSES IN BIOLOGICAL SCIENCES ON SCIENCE \\ TEACHING IN BASIC EDUCATION
}

\section{REMINISCENCIAS DE LICENCIAS EN CIENCIAS BIOLÓGICAS EN LA ENSEÑANZA DE CIENCIAS EN LA EDUCACIÓN BÁSICA}

\author{
Larissa Lunardi \\ Universidade Federal da Fronteira Sul - Brasil
}

Rúbia Emmel

Instituto Federal Farroupilha - Brasil

\begin{abstract}
Resumo: Este estudo é um recorte de uma pesquisa de Mestrado em Ensino de Ciências, que tem como objetivo analisar o modelo de investigação-formação-ação (IFA) nos processos de formação inicial de professores de Ciências e Biologia, e sua relação com as metodologias do ensino de Ciências. Esta pesquisa apresenta uma abordagem qualitativa e documental, sendo que as análises advêm de escritas narrativas obtidas de diários de bordo, produzidas por 14 licenciandos matriculados no componente curricular Prática enquanto Componente Curricular III, de um curso de Licenciatura em Ciências Biológicas, durante a primeira aula do Estágio de Docência. A análise da pesquisa foi realizada a partir da Análise Textual Discursiva (ATD) e pelos processos de unitarização, categorização e comunicação. A partir da ATD emergiram categorias diferentes, e, com estas, metatextos que originaram duas espirais reflexivas: A) Histórias e memórias dos licenciandos sobre as aulas de Ciências durante a Educação Básica; e B) Memórias dos licenciandos sobre as professoras de Ciências. A partir destas categorias, pudemos perceber que as escritas narrativas permitem aos licenciandos, no movimento de IFA, dar voz às reminiscências envolvendo o ensino de Ciências na Educação Básica e à reflexão em seu processo de formação inicial, logo, de constituição docente.
\end{abstract}

Palavras chave: Metodologia. Ensino de Ciências. Formação Inicial de professores.

\begin{abstract}
This study is an excerpt from a Master's Degree in Science Teaching research, which aims to analyze the research-formation-action (IFA) model in the initial formation processes of Science and Biology teachers, and its relationship with the methodologies of the Science teaching. This research presents a qualitative and documentary approach, and the analysis comes from narrative writings in logbooks, produced by the 14 undergraduates, enrolled in the curricular component Practical as Curricular Component III in a course in Biological Sciences, during the first class of the course. Teaching Internship. The research analysis was carried out using the principles of Textual Discourse Analysis (DTA): unitarization, categorization and communication. From the ATD, different categories emerged and, with this, metatexts that originated two reflective spirals: A) Stories and memories of the
\end{abstract}


undergraduate students about Science classes during Basic Education; and B) Teachers' memories of science teachers. Therefore, the narrative writings allow the graduates in the IFA movement to give voice to the reminiscences involving the teaching of Sciences in Basic Education and the reflection in their process of initial formation and teacher constitution.

Keywords: Methodology. Science teaching. Initial teacher formation.

Resumen: Este estudio es un extracto de una investigación del Máster en Docencia Científica, que tiene como objetivo analizar el modelo investigación-formación-acción (IFA) en los procesos de formación inicial del profesorado de Ciencias y Biología, y su relación con las metodologías de la enseñanza de las ciencias. Esta investigación presenta un enfoque cualitativo y documental, y el análisis proviene de escritos narrativos en cuadernos de bitácora, producidos por los 14 estudiantes universitarios, inscritos en el componente curricular Práctico como Componente Curricular III en un curso de Ciencias Biológicas, durante la primera clase del curso. Prácticas Docentes. El análisis de la investigación se realizó a través de los principios del Análisis del discurso textual (DTA): unitarización, categorización y comunicación. Del ATD, surgieron diferentes categorías y, con esto, metatextos que originaron dos espirales reflexivas: A) Historias y recuerdos de los estudiantes universitarios sobre las clases de Ciencias durante la Educación Básica; y B) los recuerdos de los profesores de los profesores de ciencias. Por lo tanto, los escritos narrativos permiten a los graduados en el movimiento IFA dar voz a las reminiscencias que involucran la enseñanza de las ciencias en la educación básica y la reflexión en su proceso de formación inicial y constitución docente.

Palabras clave: Metodología. Enseñanza de las ciencias. Formación inicial del profesorado.

\section{Introdução}

Este estudo é um recorte de uma pesquisa de Mestrado em Ensino de Ciências, que tem como temática as compreensões de professores em formação inicial acerca das metodologias do ensino de Ciências. O movimento formativo foi analisado a partir de escritas narrativas produzidas pelos licenciandos, com a finalidade de refletir sobre suas experiências e (re)pensar suas futuras práticas, processo mediado pela investigação-formação-ação (IFA) (GÜLLICH, 2012).

Neste sentido, evidenciamos que "escrever sobre o que se faz e o que se sente, tornouse um recurso de pesquisa para se analisar e avaliar o cotidiano social e a prática profissional" (MARTINS et al., 2010, p. 2). Assim, considerando que as experiências vêm sendo utilizadas como caminho para a reflexão, utilizamos as narrativas dos licenciandos como "caminho reflexivo para a prática docente e, portanto, para a formação desses futuros professores" (GASTAL; AVANZI, 2015, p. 150).

As reflexões estão alicerçadas no "saber da experiência", ou seja, "o que se adquire no modo como alguém vai respondendo ao que vai lhe acontecendo ao longo da vida e no modo como vamos dando sentido ao acontecer do que nos acontece" (LARROSA, 2002, p. 27). Por 
isso, este saber é único, diferente para cada sujeito, já que suas experiências são distintas, bem como as reflexões realizadas sobre elas.

Desse modo, as narrativas permitem "um movimento reflexivo do narrador sobre a experiência" (GASTAL; AVANZI, 2015, p. 153). Com isso, os licenciandos têm a possibilidade de revisitar momentos vividos quando eram alunos da Educação Básica, pois "mesmo o estudante que ainda não foi docente traz, pela sua vivência como tal, conhecimentos construídos durante a sua trajetória de vida" (GONÇALVES; GONÇALVES, 1998, p. 108), logo, este processo pode contribuir para a formação como futuros professores.

Segundo Pimenta (2009, p. 20) "quando os alunos chegam ao curso de formação inicial, já têm saberes sobre o que é ser professor. Os saberes de sua experiência de alunos que foram de diferentes professores em toda sua vida escolar”. Tais memórias fazem parte da construção da identidade profissional, que se iniciou na escola e continua durante todo o período de exercício profissional (MARCELO GARCIA, 2010).

Neste contexto, este artigo tem por objetivo analisar o modelo de IFA nos processos de formação inicial de professores de Ciências e Biologia, e sua relação com as metodologias do ensino de Ciências. O processo de IFA se desenvolveu durante o Estágio de Docência no Ensino Superior, com a intenção de analisar escritas narrativas de diários de bordo dos licenciandos, para identificar os movimentos formativos experienciados pelos sujeitos.

\section{Investigação-formação-ação na formação de professores}

Acreditamos que os processos de constituição docente nos cursos de formação podem preparar profissionais que entendam seu papel social, necessário para a construção de uma educação democrática de futuros cidadãos, e para abandonar a concepção de professor como um mero transmissor de conhecimentos (IMBERNÓN, 2011). Também neste processo, está a importância da pesquisa na formação inicial como elemento fundamental para a formação do professor pesquisador (EMMEL, 2015). Neste estudo, os licenciandos foram desafiados a investigar sua própria experiência, resgatando suas memórias, considerando que estas dotamse de grande influência à futura prática docente.

Um dos modelos para a formação docente, que assume discursos semelhantes aos aqui propostos, é a investigação-ação (IA), isto é, “[...] uma forma de entender o ofício docente que integra a reflexão e o trabalho intelectual na análise das experiências que se realizam, como um elemento essencial do que constitui a própria prática educativa" (CONTRERAS, 1994, p. 11, tradução nossa). 
A IA passou pela compreensão de diferentes perspectivas: técnica, prática e crítica (GÜLLICH, 2012). A concepção técnica buscou a integração entre experimentação científica e ação social, mas como pesquisadores se basearam apenas na observação da ação, tal abordagem não se fez efetiva no contexto da educação. A IA prática buscou a significação de princípios pedagógicos em contexto prático. Por fim, a IA crítica tem caráter coletivo, como um processo de transformação das práticas, a fim de melhorá-las e modificar seu contexto (GÜLLICH, 2012).

Sob tais preceitos, o instrumento utilizado para guiar a reflexão (PORLÁN; MARTÍN, 1997) diz respeito aos diários de bordo, os quais foram escritos pelos licenciandos por meio de narrativas sobre suas próprias experiências. A partir delas, os licenciandos puderam refletir sobre, na e para a ação. Desse modo se amplia, para este estudo, o conceito de investigaçãoação como uma categoria formativa, isto é, investigação-formação-ação (ALARCÃO, 2011; GÜLLICH, 2012; EMMEL, 2015).

O modelo IFA, proposto por Güllich (2012), reúne três enfoques fundamentais para a constituição docente: a investigação, que agrupa os movimentos de pesquisa; conceitualização e sistematização do que se investiga; a formação, que relaciona os conteúdos e conceitos; e a ação, a própria prática docente e as estratégias didáticas.

A partir da investigação-formação-ação, assumida nesta pesquisa por nós, professoras formadoras enquanto pesquisadoras de segunda $\operatorname{ordem}^{1}$, foi possível analisar as reflexões sobre a constituição docente, reveladas nas escritas narrativas dos licenciandos sobre suas próprias experiências obtidas em aulas da Educação Básica, evidenciando memórias em sua formação como alunos, e, agora, como futuros docentes.

Nas narrativas analisamos o que Carvalho e Gil-Pérez (2011) denominam de pensamento docente espontâneo, que diz respeito à formação docente adquirida ao longo dos anos em que o sujeito foi aluno, a partir do contato com seus próprios professores da Educação Básica. Tal pensamento é identificado posteriormente, na prática docente, como um comportamento docente espontâneo (CARVALHO; GIL-PÉREZ, 2011), que faz parte também da sua constituição docente.

Partindo deste elemento formativo, propomos uma análise sobre as reflexões dos alunos acerca das metodologias de ensino de Ciências. Não obstante, consideramos que "[...] a pesquisa-ação, a aprendizagem a partir da experiência e a formação com base na reflexão, têm muito elementos em comum” (ALARCÃO, 2011, p. 49-50), tais como a constituição de

\footnotetext{
${ }^{1}$ De acordo com Elliott (1990), é possível compreender os pesquisadores de segunda ordem como investigadores de escritas narrativas das histórias e experiências de outros pesquisadores (licenciandos).
} 
professores intelectuais, participativos e capazes de trabalhar coletivamente, para contribuir com a mudança do ambiente escolar e social em que vivem.

Com o intuito de possibilitar um maior contato entre os investigadores-ativos (professores formadores e licenciandos da PeCC III), a pós-graduanda (aqui autora, professora formadora e pesquisadora de segunda ordem) realizou o Estágio de Docência em uma turma cujos licenciandos são os sujeitos da presente pesquisa. Esta aproximação ampliou os diálogos formativos entre os agentes pesquisadores envolvidos.

\section{Metodologia}

O presente estudo se insere na área de Ensino de Ciências, e pauta-se em uma abordagem qualitativa (LÜDKE; ANDRÉ, 1986), cujos resultados advêm da análise de escritas narrativas produzidas por licenciandos de Ciências Biológicas, com base nas seguintes perguntas: como eram as aulas de Ciências durante a Educação Básica? Lembra de algum professor que marcou o ensino de Ciências? Por quê? Os elementos narrativos foram produzidos durante a primeira aula do Estágio de Docência, após a apresentação do plano de ensino, por 14 licenciandos matriculados no componente curricular Prática enquanto Componente Curricular (PeCC) III do $3^{\circ}$ semestre do curso de Licenciatura em Ciências Biológicas.

Utilizamos estas problematizações para que os licenciandos refletissem sobre suas experiências como alunos. A partir das memórias descritas e dos questionamentos propostos foi possível analisar a concepção dos licenciandos sobre as metodologias de ensino e outros aspectos de sua formação.

O diário de bordo foi utilizado como instrumento de construção de dados, pois já é familiar dos licenciandos, que o usam desde o $2^{\circ}$ semestre do curso. Esta ferramenta se torna um guia que torna possível a reflexão sobre a prática (BONOTTO; LEITE; GÜLLICH, 2016; PORLÁN; MARTÍN, 1997; EMMEL, 2015). De acordo com Porlán e Martín (1997), o diário é um recurso metodológico que favorece "o estabelecimento de conexões significativas entre conhecimento prático e conhecimento disciplinar, o que permite uma tomada de decisões mais fundamentada" (p. 20, tradução nossa), e "propicia o desenvolvimento dos níveis descritivos, analítico-explicativos e valorativos do processo de investigação e reflexão do professor" (p. 20, tradução nossa).

Para preservar a identidade dos licenciandos que consentiram em participar da pesquisa, por questões éticas, foram criados códigos para identificá-los. Assim, foram 
nomeados por uma letra "L" (licenciando), seguida de numeração em ordem crescente: L1, L2 até L14.

A análise da pesquisa foi realizada por meio dos princípios da Análise Textual Discursiva (ATD) (MORAES, 2003; MORAES; GALIAZZI, 2016). Esta análise se estrutura nas seguintes etapas: unitarização - em que são fragmentados os textos elaborados por meio das interpretações e compreensões dos trabalhos, emergindo, assim, unidades de significado (US); categorias temáticas - são estabelecidas relações entre as unidades de significado, que são agrupadas de acordo com suas semelhanças semânticas; comunicação - elaboraram-se textos descritivos e interpretativos (metatextos) sobre as categorias temáticas. De acordo com a abordagem analítica, as escritas narrativas passam a ser denominados de corpus da pesquisa, e são apresentadas no artigo em destaque tipográfico itálico. Cada problematização originou um corpus, totalizando dois corpus nessa pesquisa.

Cada problematização desencadeou movimentos formativos os quais apresentamos como espirais reflexivas, que situam os contextos em diferentes temas e situações da formação inicial dos professores de Ciências Biológicas (EMMEL, 2015). Cada espiral reflexiva originou ciclos reflexivos, ou seja, originou as categorias e os metatextos constituídos a partir da ATD e das reflexões das escritas narrativas. Estes ciclos orientam a direção do processo formativo, permitindo avanços teóricos e constitutivos dos sujeitos da pesquisa, além de propor novas investigações (CONTRERAS, 1994).

\section{Resgatando as reminiscências do tempo na Educação Escolar Básica: as aulas, as metodologias de ensino e professores de Ciências}

A análise dos dados foi realizada a partir da desconstrução do corpus de pesquisa, originando US que foram selecionadas por responderem à pergunta problematizadora. Aproximamos as ideias trazidas em cada US a fim de constituir categorias, sendo essas “opções e construções do pesquisador, valorizando determinados aspectos em detrimento de outros" (MORAES; GALIAZZI, 2016, p. 139).

Assim, a partir das escritas narrativas de cada pergunta problematizadora emergiram categorias diferentes, que são apresentadas junto do metatexto que elas originaram. Considerando que cada problematização originou um corpus e que as US podem pertencer a mais de uma categoria, seguem as análises.

Nesta IFA, as espirais reflexivas se constituem das problematizações, que, por sua vez, desencadearam ciclos reflexivos, demarcados pelas categorias e metatextos que emergem da 
ATD. Com isso, emergiram duas espirais reflexivas - A) Histórias e memórias dos licenciandos sobre as aulas de Ciências durante a Educação Básica; e B) Memórias dos licenciandos sobre as professoras de Ciências - e quatro ciclos reflexivos: A.1) Resgatando as aulas de Ciências do lugar de aluno da Educação Básica; A.2) Resgatando as aulas de Ciências do lugar de alunos da Licenciatura em Ciências Biológicas; e B.1) O fazer docente; B.2) O ser docente.

\section{Espiral Reflexiva A) Histórias e memórias dos licenciandos sobre as aulas de Ciências durante a Educação Básica}

A pergunta "Como eram as aulas de Ciências durante a sua Educação Básica?" norteou a busca nas escritas narrativas dos licenciandos para o desenvolvimento escrito de determinadas memórias. A partir da unitarização, foram constituídas 22 US, formadas por palavras ou expressões que respondessem à pergunta problematizadora.

Identificamos que os licenciandos escreveram, sobre as metodologias de ensino, estratégias ou recursos que estiveram presentes durante o período que passaram na escola de Educação Básica. A questão não trazia explicitamente o termo "metodologia", mas acreditamos que a palavra "como" tenha direcionado as respostas para tal perspectiva. Além disso, os licenciandos usaram adjetivos para caracterizar essas aulas. Nesse processo, emergiram dois ciclos reflexivos, que serão desenvolvidos a seguir.

\section{A.1) Resgatando as aulas de Ciências do lugar de aluno da Educação Básica}

Neste ciclo reflexivo estão contempladas as US formadas por palavras que caracterizavam as aulas da Educação Básica. Os adjetivos utilizados pelos licenciandos foram: "medianas" (US $1, \mathrm{~L} 1)$, "básicas" $\left(\mathrm{US}_{2}, \mathrm{~L} 2\right)$, "proveitosas" (US $\left.7, \mathrm{L6}\right)$, "dinâmicas"

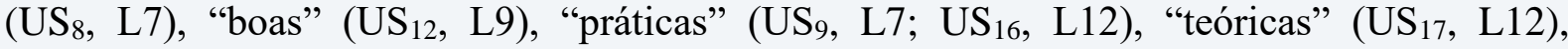
“interessantes" (US $\left.{ }_{21}, \mathrm{~L} 14\right)$, "satisfatórias" (US $\left.22, \mathrm{~L} 14\right)$.

A partir desta leitura, é possível perceber que tais narrativas apresentam uma abordagem superficial, genérica e não aprofundada, que incorpora um discurso de lugar de aluno diante das memórias das aulas e do ser professor, o qual assume um potencial transformador e investigativo ao ser incorporado e refletido na formação inicial. As US expressam que os licenciandos emitem juízo de valor, e que ainda não se apropriaram dos processos que constituem uma aula e a profissão docente em si, porque ainda não tiveram muitas experiências como professores, logo, ainda analisam as aulas como alunos. Por isso o 
saber da experiência é tão importante para a constituição docente, já que são desenvolvidos com base em seu trabalho cotidiano, na prática da profissão (TARDIF, 2006).

O que se evidenciou nas escritas narrativas tem a ver com a forma de transmissão de conteúdo, que possui resquícios do tecnicismo, abordagem de ensino tradicional (MIZUKAMI, 1986), como vemos a seguir:

As aulas eram bastante básicas. Sem muita experiência, prática e metodologias diferentes (L2, 2020).

As aulas eram expositivas, com algumas práticas $(L 8,2020)$.

Líamos o livro didático e respondíamos questões [...] (L13, 2020).

Nesta abordagem, as metodologias de ensino se restringem a aprender a utilizar técnicas, reproduzir metodologias e receitas para ensinar (CHAVES, 2013). O potencial transformador da IA e da IFA está em resgatar estas memórias, e pela via da reflexão, fazer rupturas, tecendo um professor que se reconstrói o tempo todo e que considera o saber como processo e produto de práticas sociais, e não um sujeito acumulador de métodos e técnicas.

Assim, a IFA se transformou pela defesa da IA (ALARCÃO, 2011; ELLIOTT, 1998) como uma proposta para as aulas da PeCC III, pelo aporte teórico para formar professores reflexivos (SCHÖN, 2000, ALARCÃO, 2011; ZEICHNER, 2002), que pudessem ter a pesquisa como prática recorrente em seu trabalho docente na perspectiva do professor pesquisador (ESTEBAN; ZACCUR, 2002; GARCIA; ALVES, 2002; LÜDKE et al., 2001).

A abordagem tradicional a qual nos referimos, e que acreditamos ter feito parte da vida estudantil dos licenciandos, é aquela que está presente nas aulas em que apenas o professor fala, apresenta o conteúdo e o aluno é um ser passivo que precisa absorvê-lo, sem diálogo algum. Mizukami (1986) afirma que, na abordagem tradicional, o sujeito é considerado uma tábula rasa, e que "o mundo é externo ao indivíduo" (p. 9). Isso caracteriza uma visão individualista do processo educacional e trata da concepção estática do conhecimento. De acordo com Libâneo (1992), nesta tendência predomina o ensino das Ciências pelas Ciências, com ênfase nos exercícios repetitivos e de recapitulação da matéria, exigindo uma atitude receptiva e mecânica do aluno.

Neste sentido, a aula expositiva apresentada por Krasilchik (2016) como a "modalidade didática mais comum no ensino de biologia" (p. 80), é a principal metodologia relacionada à transmissão de conteúdos. Ainda de acordo com a autora, geralmente, "os professores repetem os livros didáticos, enquanto os alunos ficam passivamente ouvindo" (KRASILCHIK, 2016, p. 80). 
Dessa maneira, é preciso compreender que a formação destes professores possivelmente foi constituída com base na racionalidade técnica, tendo reflexos em sua prática docente. Tais formações eram/são organizadas com palestras e cursos de como aprender receitas para ensinar e produzir aulas "boas" (US $\left.{ }_{12}, L 9\right)$, que servem para qualquer contexto, escola, turma e conteúdo. Isso nos leva a refletir: o que é uma boa aula?

Corazza (1996), ao reunir possíveis respostas para essa pergunta, propõe outras complementares, e por fim defende que as aulas, tendo características próprias, são construídas a partir de muitos fatores (históricos, culturais, sociais e políticos) que se constituem em espaços e tempos. Além disso, ressalta a autora que é preciso romper com a ideia de existe uma verdade da prática educacional, pois não há soluções universais e "cada professor sabe como proceder e tem uma ideia mais ou menos precisa do que quer fazer" (CORAZZA, 2012, p. 280).

Portanto, considerando que aulas tradicionais que visam a transmissão de conteúdos ainda são comuns nas escolas, precisamos constituir formações que façam com que os professores desenvolvam a capacidade de refletir sobre suas práticas e busquem modificá-las.

\section{A.2) Resgatando as aulas de Ciências do lugar de alunos da Licenciatura em Ciências Biológicas}

Ao resgatar as lembranças das aulas de Ciências na Educação Básica, os licenciandos também assumem discursos enquanto futuros professores de Ciências Biológicas, citando e descrevendo várias metodologias de ensino utilizadas pelos seus professores nas aulas de Ciências. Este ciclo reflexivo é constituído por 12 US, sendo elas: "práticas" (US 3 , L3; US 10 , L8; US $\left.{ }_{15}, \mathrm{~L} 11\right)$, “explicações” (US4, L4), “questões” (US $\left.{ }_{5}, \mathrm{~L} 4 ; \mathrm{US}_{20}, \mathrm{~L} 13\right)$, “exemplos práticos do dia-a-dia" (US, L5), “expositivas" (US $\left.{ }_{11}, \mathrm{~L} 8\right)$, "livros didáticos" (US $14, \mathrm{~L} 10$; $\mathrm{US}_{18}$, L13), "trilhas" (US $\left.19, \mathrm{~L} 13\right)$. Por fim, outro licenciando escreveu que "não existiam muitos recursos" (US $\left.\mathrm{US}_{13}, \mathrm{~L} 10\right)$ durante a sua Educação Básica.

As US constituídas nesse ciclo reflexivo dão margem para uma racionalidade prática ou crítica, mas não garante que os licenciandos abandonaram a visão tecnicista. Dois licenciandos citaram aulas "expositivas" (US ${ }_{11}$, L8) e “explicações" (US 4, L4) como metodologias que eram utilizadas durante suas aulas da Educação Básica. Nas narrativas não foi definido se tais explicações e exposições eram seguidas ou não de diálogo. Ainda dentro dessa perspectiva, outros dois licenciandos citaram as "questões" (US 5, L4; US 20, L13) como estratégia de ensino nas aulas de Ciências. 
Sempre gostei de ciências, mas nunca participei muito das aulas, ouvia explicações e respondia questões (L4, 2020).

Os "livros didáticos" $\left(\mathrm{US}_{14}, \mathrm{~L} 10 ; \mathrm{US}_{18}, \mathrm{~L} 13\right)$ também foram citados, considerando que são recursos de fácil acesso, geralmente distribuídos para os alunos de todas as escolas. De acordo com Geraldi (1994, p. 119), o livro didático, muitas vezes, direciona o processo pedagógico, “incorporando-se ao 'saber-fazer' do professor", o que justifica o ensino de Ciências livresco que costumamos ver nas escolas atualmente. O professor se torna dependente do livro para planejar, já que ele está presente na organização curricular, em sua formação e estudo (GÜLLICH, 2012).

Durante minha Educação Básica praticamente não existiam muitos recursos como a internet, audiovisuais, entre outros. Portanto, as aulas de Ciências baseavam-se mais nos conteúdos trazidos nos livros didáticos (L10, 2020).

Alguns licenciandos mencionaram as aulas "práticas" (US $\left.3, \mathrm{~L} 3 ; \mathrm{US}_{10}, \mathrm{~L} 8 ; \mathrm{US}_{15}, \mathrm{~L} 11\right)$, que estavam presentes, ou não, em seu ensino de Ciências e/ou Biologia.

Com muitas práticas, as professoras sempre tentavam trazer algo diferente, lembro que vimos a cebola no microscópio, minhocas com a lupa e coletamos e sistematizamos os tipos de folhas e raizes no fundamental (L3, 2020).

No fundamental não houve muitas aulas práticas devido às condições da instituição $(L 11,2020)$.

O excerto de L3 nos permite compreender a importância das atividades experimentais, bem como o excerto de L11, já que o fato de não ter aulas práticas nas aulas de Ciências chamou a atenção aos constituir as escritas narrativas das memórias de sua Educação Básica. Neste contexto, acreditamos que "uma teoria sem embasamento experimental não permite ao aluno uma compreensão efetiva dos processos de ação das ciências" (ROSITO, 2000, p. 197198). Por isso, é de extrema importância a presença da experimentação no ensino de Ciências, que, além disso, permite o contato direto dos alunos com os fenômenos e despertam o interesse dos mesmos (KRASILCHIK, 2016).

Porém, é preciso atentar que "como qualquer outro tipo de atividade de ensino, o simples contato dos alunos com a prática de laboratório não garante que tenham dela uma compreensão adequada" (CAPECCHI; CARVALHO, 2006, p. 140). Neste sentido, cabe problematizar, como sugerem Capecchi e Carvalho (2006), como as interações são estabelecidas nas práticas de laboratório, se possibilitam uma aula significativa para os alunos e se mantém relações com aspectos da cultura científica.

Outra atividade prática citada foram as "trilhas" (US $19, \mathrm{~L} 13)$. 
[...] algumas vezes fizemos trilhas durantes as aulas de biologia no ensino médio $(L 13,2020)$.

Conforme Reis et al. (2017), a saída de campo é uma estratégia interessante considerando que a aula acontece em um ambiente diferente do comum e valoriza a interação dos alunos com o meio, modificando a maneira como se enxerga a natureza. Para Krasilchik (2016), independente do lugar visitado, "os alunos devem ter um problema para resolver e, em função dele, observar e coletar dados" (p. 90), pois tais excursões necessitam de objetivos específicos que propiciem a busca por informações nesses ambientes naturais.

Alguns objetivos podem ser desenvolvidos a partir de excursões guiadas como:

Incentivar as pessoas a conhecerem um ambiente natural; Despertar o interesse pelo convívio com a natureza; Promover a sensibilização para os detalhes da natureza; Ensinar conteúdos ambientais de forma vivenciada; Conhecer o desenvolvimento sustentável de um ecossistema; Promover mudanças de comportamento; Desenvolver valores éticos em relação à natureza; Conquistar simpatizantes para a causa ambiental. (PROJETO DOCES MATAS, 2002, p. 19).

Com base nestas considerações, as aulas realizadas nesses espaços podem desenvolver olhares e percepções diferentes nos alunos, a partir da observação de outras formas de vida, relações e interações, dando mais sentido às Ciências e à Biologia.

Um licenciando mencionou que a professora buscava trazer para as aulas "exemplos práticos do dia-a-dia" (US 6 , L5). Para Chassot (2018), é necessário considerar o contexto e o cotidiano do aluno para alfabetizá-lo cientificamente. O cotidiano é importante para entender as Ciências, estas que nos auxiliam na compreensão da realidade que nos cerca.

Carvalho $(2004$, p. 3) defende que “[...] não se pode conceber hoje o ensino de Ciências sem que esse esteja vinculado às discussões sobre os aspectos tecnológicos e sociais que essa ciência traz na modificação de nossas sociedades". Debates que envolvem questões atuais como aborto e gravidez, sexualidade, racismo, drogas, fome, questões ambientais e relativas à biotecnologia (transgênicos, células-tronco e clonagem) estão presentes no cotidiano, e precisam ser discutidas na escola, principalmente nas disciplinas de Ciências e Biologia (SELLES; FERREIRA, 2005). Considerando que buscamos a formação de cidadãos críticos que participem ativamente da sociedade, a contextualização dos conteúdos trabalhados em sala de aula é fundamental para um ensino de qualidade.

As proposições enunciadas a partir das histórias e memórias dos licenciandos sobre as aulas de Ciências durante a Educação Básica, foram analisadas pelo lugar de alunos da 
Educação Básica e de professores de Ciências e Biologia em formação inicial. As escritas narrativas nos permitem compreender os movimentos formativos, que possibilitam avanços na constituição docente, partindo da análise das experiências do passado para a transformação do presente.

\section{Espiral Reflexiva B) Memórias dos licenciandos sobre as professoras ${ }^{2}$ de Ciências}

Esta análise teve como corpus de análise as escritas das narrativas dos licenciandos, a partir das histórias que demarcaram na questão: "lembra de algum professor que marcou o ensino de Ciências? Por quê?”. Resgatar as memórias da Educação Básica, seja das aulas de Ciências ou, neste foco, dos professores que marcaram o ensino de Ciências, advém da “experiência vivida" (GASTAL; AVANZI, 2015, p. 154), que considera a experiência dos sujeitos como estudantes em todo seu percurso na Educação Básica. E que "buscam revisitar momentos vividos como alunos de Educação Básica em uma perspectiva diferente, agora em busca de elementos para sua futura atuação como professores" (GASTAL; AVANZI, 2015, p. 154).

Partindo das leituras das narrativas, percebemos que alguns licenciandos não justificaram o motivo de lembrar de seus professores (L6, L12 e L13), outros lembram de maneira superficial (L1), citaram apenas nomes (L4) ou até mesmo não lembravam (L14). Porém, vários licenciandos evocaram memórias e descreveram histórias sobre suas professoras da Educação Básica, sendo que tais narrativas constituíram os dois ciclos reflexivos a seguir.

\section{B.1) O fazer docente}

Esse ciclo reflexivo é constituído por 22 US, que emergiram das escritas narrativas de 8 licenciandos (L2, L3, L5, L7, L8, L9, L10 e L11). Identificamos que esses licenciandos trouxeram excertos narrativos das formas de ensino, dos recursos e das metodologias como algo marcante no ensino de Ciências.

Ao pensarem sobre as professoras que tiveram durante o período escolar, muitos licenciandos escreveram que o mais marcante eram as metodologias (US ${ }_{12}, \mathrm{~L} 5$; US $25, \mathrm{~L} 10$; $\left.\mathrm{US}_{31}, \mathrm{~L} 11\right)$. Outros licenciandos mencionaram que tais metodologias eram diferenciadas (US $_{3}$,

\footnotetext{
${ }^{2}$ Nomeamos “professoras”, pois a maioria dos docentes citados nas narrativas eram mulheres.
} 
L2; US 4 , L2; $\left.\mathrm{US}_{11}, \mathrm{~L} 3 ; \mathrm{US}_{20}, \mathrm{~L} 9\right)$. Dentre essas, a mais citada, que foi contemplada em 5 US $\left(\mathrm{US}_{8}, \mathrm{~L} 3 ; \mathrm{US}_{9}, \mathrm{~L} 3 ; \mathrm{US}_{17}, \mathrm{~L} 7 ; \mathrm{US}_{19}, \mathrm{~L} 8 ; \mathrm{US}_{33}, \mathrm{~L} 11\right)$, foi a aula prática.

[...] e fazia atividades diferentes no laboratório. No laboratório não tinha muitos materiais, mas ela mesma trazia de casa e fazia acontecer ou pedia para nós trazermos alguns materiais (L7, 2020).

Realizamos uma atividade de observação de partes da flor e na sequência cada aluno teve que escolher uma flor e identificar as suas partes. Foi uma atividade que marcou bastante (L8, 2020).

Percebemos nos excertos acima um fazer docente para além da racionalidade técnica, ou seja, para além da passividade do processo de ensino pautado na mera transmissão e recepção. Nestes excertos os professores são lembrados pelo seu fazer docente e por tornar os alunos sujeitos ativos: "pedia para nós trazermos alguns materiais" (L7, 2020), "cada aluno teve que escolher uma flor" (L8, 2020). Tais ações aumentam a participação do aluno em sala de aula, desenvolvem sua curiosidade e despertam o interesse sobre os assuntos das Ciências. Fica evidente como atividades práticas, que podem ser realizadas em qualquer ambiente, não necessariamente no laboratório e com materiais acessíveis, marcam o ensino de Ciências.

Um licenciando, que cursou o magistério durante o Ensino Médio, comentou que a professora de Biologia era também professora de Didática das Ciências, e que além de utilizar a experimentação nas suas aulas, ensinava seus alunos a planejar aulas com atividades experimentais $\left(\mathrm{US}_{10}, \mathrm{~L} 3\right)$.

A prof. Elisa $a^{3}$ sempre fazia experiências, mesmo a escola mal tendo laboratório, ela trazia coisas de casa para fazer as experiências. Quando ela foi professora de Didática das Ciências ela ensinava a gente a planejar aulas práticas, a dar aulas diferentes, mesmo a escola não tendo laboratório (L3, 2020).

Essa dificuldade para desenvolver atividades experimentais foi identificada nas narrativas de alguns licenciandos (L3, L7 e L10), e é uma realidade de muitos professores da Educação Básica. Dentre as dificuldades citadas pelos docentes estão a falta de equipamentos, materiais e/ou de laboratórios; a falta de tempo para preparação desse material; e falta de segurança e conhecimentos para desenvolver essas atividades (KRASILCHIK, 2016). Entretanto, é possível realizar experimentos na própria sala de aula, ou fora dela, utilizando materiais de baixo custo e acessíveis (ROSITO, 2000), como identificado nas narrativas de L3 e L7.

\footnotetext{
${ }^{3}$ Utilizamos nomes fictícios quando a narrativa apresentava o nome da professora.
} 
Também, como atividades que marcaram a presença das professoras para os estudantes, foram citados o diálogo $\left(\mathrm{US}_{13}\right.$, L5), a relação dos conteúdos com o cotidiano (US $\left.{ }_{26}, \mathrm{~L} 10\right)$, uma roda de conversa (US $\left.{ }_{27}, \mathrm{~L} 10\right)$, uma saída de campo $\left(\mathrm{US}_{28}, \mathrm{~L} 10\right)$ e o uso de vídeos (US $\left.{ }_{29}, \mathrm{~L} 10\right)$, como vemos a seguir:

\begin{abstract}
O que mais me marcou nas duas [professoras] foi a metodologia, porque existia um diálogo entre a turma e elas (L5, 2020).

No entanto, falando especificamente das aulas de Ciências, alguns professores marcaram essa trajetória pela forma como abordavam os conteúdos trabalhados, buscando aproximar aqueles assuntos descritos em textos ao cotidiano. Isso era feito de forma simples, porém deixavam aprendizados significativos. Uma roda de conversa fora das paredes da escola com a turma da sétima série, ano que eram estudados os assuntos relativos ao corpo humano, deixando abertura para questionamentos, com esforço docente para desmistificar conceitos errôneos a respeito de tal assunto. A visita até um córrego para a localização de girinos, a fim de melhor compreendermos os processos de metamorfose em anfíbios. A exibição de vídeos e mais tarde as imagens em lâminas de retroprojetor que eram trazidos pela professora, sempre esperados com entusiasmo, pois era somente na escola que tinha acesso aos mesmos (L10, 2020).
\end{abstract}

Moraes e Ramos (1988, p. 120) ao responderem “como ensinar Ciências?” apontam algumas características que precisam ser refletidas no planejamento das aulas, como

[...] o envolvimento ativo dos alunos, a construção do próprio conhecimento, a vivência de situações abordando conceitos e princípios relevantes, integrados à realidade e com um significado social.

A partir das narrativas de L5 e L10, percebemos que algumas destas características foram pensadas pelas professoras e foram tão significativas que marcaram não só as aulas, mas também as práticas que desenvolviam. Estes excertos nos mostram a importância do "P de prática", um dos elementos essenciais na constituição docente de acordo com Nóvoa (2009), que pode sempre estar centrada na aprendizagem dos alunos.

Um dos licenciandos situa o contexto de sua Educação Básica, em que não havia muitos recursos tecnológicos disponíveis $\left(\mathrm{US}_{23}, \mathrm{~L} 10\right)$ :

A realidade escolar durante o transcorrer da minha Educação Básica era diferente da forma como se apresenta nos dias atuais. Internet, computadores e muitos dos recursos facilitadores para o processo de ensino não eram disponíveis, tampouco existiam. Nesse contexto, o livro didático imperava como principal recurso utilizado pelos professores, juntamente com o quadro negro (L10, 2020).

Observamos que, apesar dessa falta de recursos tecnológicos, suas professoras proporcionaram vivências significativas em Ciências como apresentado anteriormente em 
outro excerto da escrita narrativa do licenciando. L10 ainda menciona o uso do livro didático (US $\left.7, L 2 ; \mathrm{US}_{24}, \mathrm{~L} 10\right)$ como principal ferramenta utilizada pelas docentes. De acordo com Güllich (2012), o professor muitas vezes se torna dependente do livro para planejar pela forte presença deste na organização curricular, formação e estudo. Com isso, é possível perceber a influência que o livro didático pode ter nas escolhas metodológicas dos professores, uma vez que esse recurso se torna a base para o planejamento das aulas de Ciências

\section{B.2) O ser docente}

Esse ciclo reflexivo é constituído por 11 US, que emergiram das escritas narrativas de 6 licenciandos (L2, L5, L7, L9, L10 e L11), os quais mencionaram aspectos da pessoa que é a professora de Ciências. Assim, nos excertos que seguem identificamos que os licenciandos relataram o modo de ser e de agir de suas professoras da Educação Básica, ao evocarem memórias sobre a escola.

Um licenciando escreveu que a professora gostava de ensinar $\left(\mathrm{US}_{1}, \mathrm{~L} 2\right)$.

[...] foi a professora da $6^{a}$ e $7^{a}$ séries (era a mesma professora), a qual demonstrava um amor enorme pelo ensino e pela matéria, tornando o aprendizado produtivo e gostoso de estudar. Sempre tinha algo novo, e se esforçava para trazer uma metodologia diferenciada $(L 2,2020)$.

Segundo Nóvoa (2013, p. 17), “a maneira como cada um de nós ensina está diretamente dependente daquilo que somos como pessoa quando exercemos o ensino". Nesse contexto, um dos "P"s que constituem o professor, é o "P de pessoa", já que as capacidades de se relacionar e de se comunicar são fundamentais para o ser docente (NÓVOA, 2009).

L2 também escreve que outra professora parecia não gostar da profissão (US ${ }_{5}$, L2; $\left.\mathrm{US}_{6}, \mathrm{~L} 2\right)$ :

[...] era a professora do ensino médio (foi a mesma nos 3 anos), a qual parecia não gostar do ensino, representava que o mesmo era um peso, o tornando algo difícil e cansativo, não tinha uma metodologia diferenciada resumindo o ensino em texto, livro e prova $(L 2,2020)$.

A partir deste excerto, compreende-se, como Goodson (2013) explica, que as narrativas constituem dados de pesquisa relevantes, pois revelam os sentidos do "eu", da pessoa que escreve e de sua subjetividade, no ensino pelas experiências de vida e o ambiente sociocultural. No caso deste trecho, tais sentidos são revelados da perspectiva de outro sujeito, do aluno, sobre sua professora de Ciências da Educação Básica. Assim, é possível compreender a relação entre o ambiente sociocultural e as narrativas, pois evidencia o quanto 
os professores podem influenciar de modo significativo as escolhas de seus estudantes. Esse processo fornece o que Goodson (2013) refere como "modelo funcional" (p. 72): são docentes que "influenciaram provavelmente a visão subsequente da pedagogia desejável, e bem assim, possivelmente, a escolha do próprio curso" (ibid.).

Nesse sentido, os licenciandos escreveram sobre a dedicação e preocupação das professoras, principalmente, no intuito de envolver e incentivar os alunos, fazendo-os se interessar pelo componente curricular e pelos estudos $\left(\mathrm{US}_{2}, \mathrm{~L} 2 ; \mathrm{US}_{14}, \mathrm{~L} 5 ; \mathrm{US}_{15}, \mathrm{~L} 5 ; \mathrm{US}_{18}\right.$, L7; $\mathrm{US}_{21}, \mathrm{~L} 9 ; \mathrm{US}_{22}, \mathrm{~L} 9 ; \mathrm{US}_{32}$, L11). Abaixo constam alguns exemplos:

[...] elas faziam a turma pensar e gostar do assunto que estavam ensinando, conduziam a aula incentivando o pessoal a questionar e elaborar algum raciocínio $(L 5,2020)$.

[...] despertando assim o interesse de toda a turma. Era uma professora do ensino médio, onde todos gostavam muito de suas aulas e do seu modo de ensinar (L9, 2020).

[...] a importância que davam para a nossa compreensão [...] $(L 11,2020)$.

L10 citou a importância de alguns momentos da sua formação (US S30 $_{3}$ L10) para a sua constituição como estudante e ser humano, e questionamos: por que não como professora também?

São lembranças marcantes que carrego comigo, com ensinamentos fundamentais ao meu processo formativo enquanto aluna, como também na minha constituição humana (L10, 2020).

Esta narrativa apresenta o motivo pelo qual utilizamos o diário de bordo: refletir sobre as memórias e ações que constituem os futuros docente, fazendo-os escrever, ler, interpretar e reinterpretar suas escritas, para pensar e transformar o ser e fazer docentes, em todo o processo formativo, que é, e precisa ser, contínuo e permanente. Nesse contexto, Chaves (2005, p. 88) afirma que:

As memórias evocadas revelam como o passado e presente estão intimamente relacionados à constituição de nosso fazer docente e, ainda, que evocá-las mostra-se um caminho fecundo à medida que as reminiscências dos sujeitos dessa narrativa ensinaram-lhes (ao mesmo tempo em que nos ensinam) a compreender e transformar suas maneiras de ser e de estar na docência.

Pela maneira como os licenciandos escreveram (na maioria das narrativas), percebemos que as professoras da Educação Básica marcaram o ensino de Ciências, pois foi tão admirado por eles, fazendo-os escolher este como o seu próprio caminho. "Um bom professor pode influenciar muito na escolha profissional ou no gosto de alguém por uma 
determinada área" (BREMM; GÜLLICH, 2018, p. 263). Com isso, seguimos questionando: quem sabe foram estas professoras/pessoas que inspiraram os licenciandos a seguirem pela docência?!

\section{Seguimos refletindo sobre as reminiscências...}

Identificamos que as narrativas dos licenciandos possuem um caráter bastante descritivo, em virtude da prática de escrita no diário de bordo ainda ser recente. De acordo com Alarcão (2011, p. 49) "é preciso fazer um esforço grande para passar do nível meramente descritivo ou narrativo para o nível em que se buscam interpretações articuladas e justificadas e sistematizações cognitivas”. Além disso, os licenciandos podem ver essa atividade de escrita apenas como uma tarefa avaliativa do componente curricular (GASTAL et al., 2010). No sentido de provocar a reflexão é que buscamos utilizar no processo de investigação-formaçãoação perguntas problematizadoras, as quais deram origem a esta pesquisa.

Outro aspecto a se analisar é a diversidade da turma que cursou o componente de PeCC III, pois também justifica as escritas serem mais descritivas ou reflexivas, ou ainda pouco e muito desenvolvidas. Algumas licenciandas cursaram o magistério, outros já cursaram metade da licenciatura ou são formandos; alguns se formaram no Ensino Médio recentemente, outros há muito tempo; e há aqueles que já são docentes dos anos iniciais. Essa diversidade possibilita muitas trocas de experiências e de concepções sobre as Ciências e sobre a docência, enriquecendo assim os diálogos durante as aulas. Neste sentido, Carniatto (2002, p. 28) propõe "compor um mosaico vibrante com as cores vivas das vidas desses alunos".

Percebemos que as metodologias de ensino aparecem intrinsecamente em todo processo, como elementos marcantes das aulas e dos próprios professores que as utilizavam. Nas escritas narrativas analisamos que os licenciandos teceram opiniões e visões, em sua maioria, como alunos (do alto da montanha) e não como professores (da planície) (GASTAL et al., 2010). A partir disso emergem outros questionamentos resultantes desse processo de análise, que demonstram que a investigação continua: os licenciandos se enxergam docentes? Como? Como serão as aulas de Ciências desses futuros docentes? Não apenas nos estágios, mas também em contextos parecidos com aqueles em que estavam os professores que ministraram as aulas narradas no recorte histórico-temporal. Será que as aulas serão diferentes? Os licenciandos pensam na diferença de variáveis (tempo, espaço,...) envolvidas quando se é estagiário e quando se é docente? E nos recursos e espaços oferecidos pelas 
escolas de Educação Básica? O que ocasionou/ocasiona este contraste de metodologias entre espaços escolares diferentes? Que cenários os futuros docentes irão permitir constituir em sua prática docente? Como será quando estes licenciandos descerem da montanha e começarem a enxergar na planície? Como serão as memórias e histórias dos alunos destes licenciandos?

A partir destas reflexões, é possível pensar que é provável que os futuros professores considerem suas experiências ao realizar planejamentos, práticas de ensino e estágio de regência em Ciências/Biologia durante o curso. Compreendemos a importância de resgatar as memórias, para a realização do espelhamento de práticas, que "por contemplar a análise de situações homólogas, possibilita que os professores avaliem, reconsiderem e reformulem as suas próprias práticas pedagógicas" (SILVA; SCHNETZLER, 2000, p. 51), refletindo sobre suas experiências discentes. Além disso, o próprio ato de refletir estar presente em sua formação, acaba por fazer parte da sua constituição docente, forjando identidades docentes, aproximando o sujeito de um profissional reflexivo e crítico, que investiga a sua própria prática.

\section{Considerações Finais}

Pudemos perceber, a partir da IFA proposta, que as escritas narrativas dos licenciandos são relevantes pela riqueza de experiências e interações humanas. Para além das nossas análises e reflexões enquanto investigadoras ativas, a pesquisa também apresentou exercícios de leitura que os licenciandos fizeram dos acontecimentos de sua formação enquanto estudantes da Educação Básica. Tais atividades, ao mesmo tempo, visaram a escrita de um texto endereçado a outro, composto por memórias refletidas em sua constituição na formação inicial de professores.

Destacamos que nesta pesquisa o resgate das memórias, ocorreu a partir de uma nova dinâmica espaço e tempo: agora não mais como alunos, mas em contexto de formação inicial de professores reflexivos. Resultaram da ATD ciclos reflexivos que, em diferentes contextos, nos permitiram investigar sobre as reflexões dos licenciandos, que assumem duplo sentido, do lugar de aluno da Educação Básica ao lugar de licenciando em Ciências Biológicas.

Os diálogos nos contextos formativos da PeCC III se refletiram em narrativas que possibilitaram perceber os imaginários do pensamento e da ação sobre a constituição docente, bem como as histórias de vida e trajetórias da Educação Básica envoltas nas escolhas profissionais de cada licenciando. 
De tais análises, manifestamos outra pergunta: será que os licenciandos estão percebendo que as metodologias de ensino podem ir além da técnica? Este processo de IFA buscou ir além da racionalidade técnica ou prática, e desenvolver a racionalidade crítica e emancipatória. O resgate das memórias da Educação Básica é o que permite, neste estudo, assumir a reflexão como categoria formativa.

Assim, as perguntas problematizadoras permitem aos licenciandos dar voz às reminiscências, envolvendo o ensino de Ciências na Educação Básica, que vem marcando suas identidades. Neste sentido, permitem a reflexão sobre a sua constituição docente e a indissociabilidade dos métodos e estratégias descritos, que passaram a ser refletidos e analisados num processo mediado pela investigação-formação-ação.

\section{REFERÊNCIAS}

ALARCÃO, I. Professores reflexivos em uma escola reflexiva. 8 ed. São Paulo: Cortez, 2011.

BONOTTO, D. L.; LEITE, F. A; GÜLLICH, R. I. C. (org). Movimentos formativos: desafios para a Educação em Ciências e Matemática. 1 ed. Tubarão: Ed. Copiart, 2016.

BREMM, D.; GÜLLICH, R. Dos cheiros às memórias da escola: Formação e docência em Ciências Biológicas. Contexto \& Educação, v. 33, n. 106, p. 254-270, 2018.

CAPECCHI, M. C. V. M.; CARVALHO, A. M. P. Atividade de laboratório como instrumento para a abordagem de aspectos da cultura científica em sala de aula. ProPosições, v. 17, n. 1, jan./abr. 2006.

CARNIATTO, I. A formação do sujeito professor: investigação narrativa em ciências/biologia. Cascavel: Edunioeste, 2002.

CARVALHO, A. M. P.; GIL-PÉREZ, D. Formação de professores de Ciências: tendências e inovações. 10 ed. São Paulo: Cortez, 2011.

CARVALHO, A. M. P. Critérios estruturantes para o ensino das Ciências. In.: CARVALHO, A. M. P. (Org). Ensino de ciências: unindo a pesquisa e a prática. São Paulo: Cengage Learning, 2004. p. 1-17.

CHASSOT, A. Alfabetização científica: questões e desafios para a educação. 8 ed. Ijuí: Editora Unijuí, 2018.

CHAVES, S. N. Memórias de formação: reminiscências de formadores de professores sobre suas maneiras de ver e ser na docência. Amazônia: Revista de Educação em Ciências e Matemáticas. v. 1, n. 2, p. 87-92, jan/jun 2005.

CHAVES, S. N. Reencantar a ciência, reinventar a docência. São Paulo: Editora Livraria da Física, 2013. 
CONTRERAS, J. D. La investigación en la acción. Cuadernos de Pedagogia, n. 224, Madrid: Morata, p. 7-31, abr./1994.

CORAZZA, S. M. “Como dar uma aula?” Que pergunta é esta? In: MORAES, V. R. P. (org.). Melhoria do ensino e capacitação docente: programa de aperfeiçoamento pedagógico. Porto Alegre: Ed. UFRGS, 1996, p. 57-63.

CORAZZA, S. M. Didaticário de criação: aula cheia, antes da aula. Anais do XVI Encontro Nacional de Didática e Práticas de Ensino, ENDIPE, UNICAMP, Campinas, p. 278-284, 2012.

ELLIOTT, J. La investigación-acción en educación. Madrid: Ediciones Morata, 1990.

ELLIOTT, J. Recolocando a Pesquisa-ação em seu lugar original e próprio. In: GERALDI, C.; FIORENTINI, D.; PEREIRA, E. (orgs.). Cartografias do trabalho docente: professor(a) pesquisador(a). Campinas: Mercado de letras, 1998. p. 137-152.

EMMEL, R. O currículo e o livro didático da Educação Básica: contribuições para a formação do Licenciando em Ciências Biológicas. 2015. Tese (Doutorado em Educação nas Ciências) - Universidade Regional do Noroeste do Estado do Rio Grande do Sul (Campus Ijuí). Ijuí, 2015.

ESTEBAN, M. T.; ZACCUR, E. (Orgs.). Professora-pesquisadora: uma práxis em construção. Rio de Janeiro: DP\&A, 2002.

GARCIA, R. L.; ALVES, N. Conversa sobre pesquisa. In.: ESTEBAN, M. T.; ZACCUR, E. (Orgs.). Professora-pesquisadora: uma práxis em construção. Rio de Janeiro: DP\&A, 2002. p. 97-117.

GASTAL, M. L. A.; AVANZI, M. R. Saber da experiência e narrativas autobiográficas na formação inicial de professores de biologia. Ciência e Educação, Bauru, v. 21, n. 1, p. 149$158,2015$.

GASTAL, M. L.; AVANZI, M. R.; ZANCUL, M. S.; GUIMARÃES, Z. F. S. Da montanha à planície: narrativas e formação de professores de Ciências e Biologia. Revista da SBEnBIO, n. 3, p. 1252-1260, out 2010.

GERALDI, C. M. G. Currículo em ação: buscando a compreensão do cotidiano da escola básica. Pro-posições, v. 5, n. 3, nov./1994.

GOODSON, I. F. Dar voz ao professor: as histórias de vida dos professores e o seu desenvolvimento profissional. In.: NÓVOA, A. Vida de professores. 2 ed. Porto: Porto Editora, 2013. p. 63-78.

GONÇALVES, T. O.; GONÇALVES, T. V. O. Reflexões sobre uma prática docente situada: buscando novas perspectivas para a formação de professores. In: GERALDI, C. M. G.; FIORENTINI, D.; PEREIRA, E. M. A. (org.). Cartografias do Trabalho Docente: Professor(a)-pesquisador(a). Campinas: Mercado de Letras, 1998. 
GÜLLICH, R. I. C. O livro didático, o professor e o ensino de ciências: um processo de investigação-formação-ação. 2012. Tese (Doutorado em Educação nas Ciências) Universidade Regional do Noroeste do Estado do Rio Grande do Sul, Ijuí, 2012.

IMBERNÓN, F. Formação Docente e Profissional: formar-se para a mudança e a incerteza. 9 ed. São Paulo: Cortez, 2011.

KRASILCHIK, M. Prática de Ensino de Biologia. 4 ed. São Paulo: Editora da Universidade de São Paulo, 2016.

LARROSA, J. B. Notas sobre a experiência e o saber de experiência. Revista Brasileira de Educação, n. 19, jan./fev./mar./abr. 2002.

LIBÂNEO, J. C. Democratização da escola pública: a pedagogia crítico-social dos conteúdos. São Paulo: Loyola, 1992.

LÜDKE, M.; ANDRÉ, M. E. D. A. Pesquisa em educação: abordagens qualitativas. São Paulo: EPU, 1986.

LÜDKE, M. (coord); PUGGIAN, C.; CEPPAS, F. CAVALCANTE, R. L. A.; COELHO, S. L. B. O professor e a pesquisa. Campinas: Papirus, 2001.

MARCELO GARCIA, C. O professor iniciante, a prática pedagógica e o sentido da experiência. Revista Brasileira de Pesquisa sobre Formação Docente, Belo Horizonte, v. 02, n. 03, p. 11-49, ago./dez. 2010.

MARTINS, E. F.; CARVALHO, L. C. L.; MARTINS, M.; CARVALHO, M. V. C. As narrativas e os diários de formação: caminhos possíveis na pesquisa em educação. Anais do VI Encontro de Pesquisa em Educação da UFPI, Teresina, Piauí, 2010.

MIZUKAMI, M. G. N. Ensino: as abordagens do processo. São Paulo: EPU, 1986.

MORAES, R. Uma tempestade de luz: a compreensão possibilitada pela análise textual discursiva. Bauru: Ciência e Educação, v.9, n. 2, p. 191-211, 2003.

MORAES, R.; GALIAZZI, M. C. Análise textual discursiva. 3 ed. Ijuí: Editora Unijuí, 2016.

MORAES, R.; RAMOS, M. G. Construindo o conhecimento: uma abordagem para o ensino de Ciências. Porto Alegre: SAGRA, 1988.

NÓVOA, A. Os professores e as histórias da sua vida. In: NÓVOA, A. Vida de professores. 2 ed. Porto: Porto Editora, 2013. p. 11-30.

NÓVOA, A. Professores: Imagens do futuro presente. Lisboa: EDUCA, 2009.

PIMENTA, S. G. Saberes pedagógicos e atividade docente. 7 ed. São Paulo: Cortez, 2009.

PORLÁN, R.; MARTÍN, J. El diário del professor: un recurso para investigación en el aula. Diáda: Sevilla, 1997. 
PROJETO DOCES MATAS. Brincando e aprendendo com a mata: manual para excursões guiadas. Belo Horizontes, 2002.

REIS, E. F.; PASTANA, C. O.; HENCKES, S. B. R.; MARCHI, M. I.; STROHSCHOEN, A. A. G. Saídas a campo: possibilidades de ensino e aprendizagem em ambiente não formal. Ciência em tela, v. 10, n. 1, 2017.

ROSITO, B. A. O ensino de Ciências e a experimentação. In: MORAES, R. Construtivismo e ensino de Ciências: reflexões epistemológicas e metodológicas. Porto Alegre: EDIPUCRS, 2000.

SELLES, S. E.; FERREIRA, M. S. Disciplina escolar Biologia: entre a retórica unificadora e as questões sociais. In: MARANDINO, M.; SELLES, S. E.; FERREIRA, M. S.; AMORIM, A. C. (org.) Ensino de Biologia: conhecimentos e valores em disputa. Niterói: Eduff, 2005.

SILVA, L. H. A.; SCHNETZLER, R. P. Buscando o caminho do meio: a "sala de espelhos" na construção de parcerias entre professores e formadores de professores de Ciências.

Ciência \& Educação, Bauru, v. 6, n. 1, p. 43-53, 2000.

SCHÖN, D. A. Educando o profissional reflexivo: um novo design para o ensino e a aprendizagem. Porto Alegre: Artmed, 2000.

TARDIF, M. Saberes docentes e formação profissional. 7 ed. Petrópolis: Vozes, 2006.

ZEICHNER, K. Formando professores reflexivos para uma educação centrada no aprendiz: possibilidades e contradições. In.: ESTEBAN, M. T.; ZACCUR, E. (Orgs.). Professorapesquisadora: uma práxis em construção. Rio de Janeiro: DP\&A, 2002. p. 25-52.

\section{$\underline{\text { SOBRE AS AUTORAS }}$}

\section{Larissa Lunardi}

Mestranda em Ensino de Ciências, Universidade Federal da Fronteira Sul (UFFS), Campus Cerro Largo, Brasil; Programa de Pós-Graduação em Ensino de Ciências. E-mail: larissalunardi18@gmail.com.

iD https://orcid.org/0000-0003-3434-3397

\section{Rúbia Emmel}

Doutora em Educação nas Ciências, Universidade Regional do Noroeste do Estado do Rio Grande do Sul; Docente do Instituto Federal Farroupilha (IFFAR), Campus Santa Rosa. Programa de Pós-Graduação em Ensino de Ciências, Universidade Federal da Fronteira Sul (UFFS), Campus Cerro Largo, Brasil. E-mail: rubia.emmel@iffarroupilha.edu.br.

\section{iD https://orcid.org/0000-0002-4701-8959}

